\title{
DERRIDA: DECONSTRUCCIÓN, DIFFÉRANCE Y DISEMINACIÓN. UNA HISTORIA DE PARÁSITOS, HUELLAS Y ESPECTROS
}

\section{Adolfo Vásquez Rocca ${ }^{1}$}

Pontificia Universidad Católica de Valparaíso

Universidad Complutense de Madrid

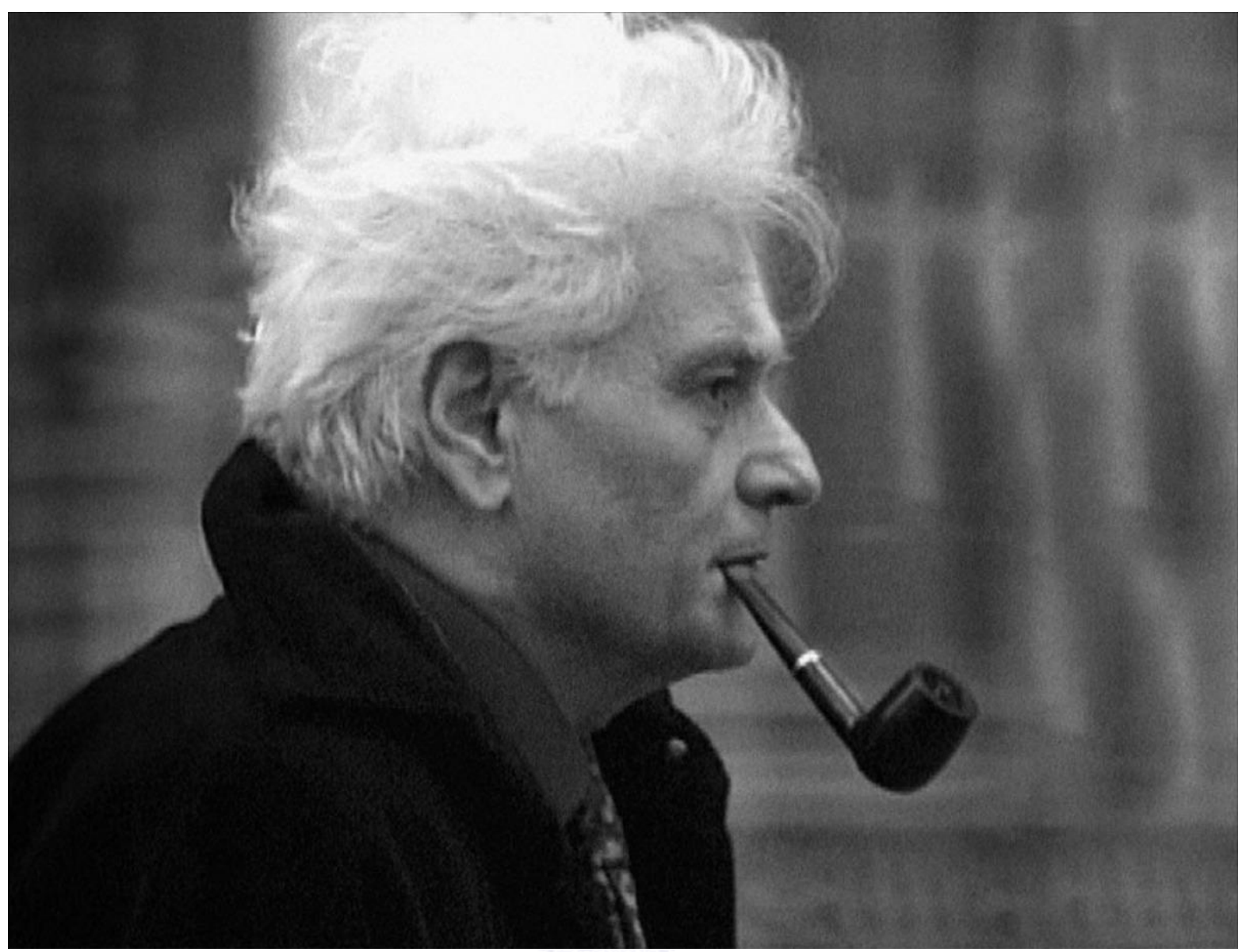

\footnotetext{
${ }^{1}$ Doctor en Filosofía por la Pontificia Universidad Católica de Valparaíso; Postgrado Universidad Complutense de Madrid, Departamento de Filosofía IV, mención Filosofía Contemporánea y Estética. -Profesor de Postgrado Instituto de Filosofía PUCV -Profesor Asociado al Grupo THEORIA (c) Proyecto europeo de Investigaciones de Postgrado [Philosophy and Social Sciences Universidad Complutense | Madri+d UCM 1391 I Eastern Mediterranean University Academia.edu. -Miembro Titular del Consejo Editorial Internacional de Errancia, Revista de Psicoanálisis, Teoría Crítica y Cultura -UNAM- Universidad Nacional Autónoma de México.Profesor Adjunto de la Escuela de Psicología UNAB. Académico Investigador de la Vicerrectoría de Investigación y Postgrado, Universidad Andrés Bello. Profesor del Magíster en Biología Cultural 2013-2014 dictado por la Escuela Matríztica de Santiago -dirigida por el Dr. Humberto Maturana- y la Universidad Mayor.
}

Web: http://www.danoex.net/adolfovasquezrocca.html 
Resumen.- La deconstrucción irrumpe en el pensamiento de la escritura, como una escritura de la escritura, que por lo pronto obliga a otra lectura: no ya imantada a la comprensión hermenéutica del sentido que quiere-decir un discurso, a su fondo de ilegibilidad y de deseo de idioma-, a las fuerzas no intencionales inscritas en los sistemas significantes de un discurso que hacen de éste propiamente un "texto", es decir, algo que por su propia naturaleza o por su propia ley se resiste a ser comprendido como expresión de un sentido, o más bien "expone" éste como efecto -y con su legalidad y necesidad específica- de una ilusión para la conciencia.

Palabras clave: Deconstrucción, huella, texto, différance, gramatología, presencia, logocéntrico, epistemología, margen, hermenéutica, arqui-escritura, des-sedimentar, diseminación.

\title{
Derrida: deconstruction, differance and spread. A history of parasites, footprints and spectra
}

\begin{abstract}
Deconstruction breaks at the thought of writing a script writing, that for now forces another read: no longer magnetized to the hermeneutic understanding of meaning he wants-make a speech, his background and desire illegibility of language-, to registered unintentional forces signifying systems of discourse that make this really a "text", ie, something that by its nature or by its own law refuses to be understood as an expression of sense, or rather "exposed" as-and this effect with its legality and necessity of an illusion specifically for consciousness.
\end{abstract}

Keywords: Deconstruction, footprint, text, differance, grammatology, presence, logocentric, epistemology, margin, hermeneutics, archi-writing, de-settling, spread.

\section{Una buena traducción debe ser abusiva² \\ Derrida}

\section{1.- La desconstrucción en las fronteras de la filosofía: hacia un ethos de la lectura.}

Derrida está en peligro de hacer lo mismo que crítica cuando produce una nueva jerga metalingüística, llena de palabras como trace y différence, y la utiliza para decir cosas de aspecto heideggeriano como "sólo sobre la base de la différence y su 'historia' podemos conocer supuestamente quiénes somos y dónde estamos 'nosotros'". En la medida en que Derrida intenta proporcionar argumentos en favor de tesis como "la escritura es anterior al habla" o "los textos se deconstruyen a sí mismos" -todos aquellos eslóganes que sus seguidores tienen la tentación de considerar como "resultados de la indagación filosófica" y como la base de un

2 DERRIDA, Jacques, La desconstrucción en las fronteras de la filosofía. La retirada de la metáfora, Ed. Paidós, Barcelona, 1989: -"La traducción es escritura. (...) Se trata de una escritura productiva inspirada por el texto original". 
método de lectura- traiciona su propio proyecto. Los peores fragmentos de Derrida son aquellos en los que empieza a imitar aquello que odia y empieza a decir que ofrece "análisis rigurosos". Los argumentos sólo funcionan si el hablante y su auditorio comparten un vocabulario en el cual establecer las premisas. Filósofos tan originales e importantes como Nietzsche, Heidegger y Derrida están forjando nuevas formas de hablar, y no realizando sorprendentes descubrimientos filosóficos sobre otras antiguas. En consecuencia, no es probable que su argumentación sea buena. ${ }^{3}$

Desconstruir parece significar ante todo: desestructurar o descomponer, incluso dislocar las estructuras que sostienen la arquitectura conceptual de un determinado sistema o de una secuencia histórica; también, desedimentar los estratos de sentido que ocultan la constitución genética de un proceso significante bajo la objetividad constituida y, en suma, solicitar o inquietar, haciendo tambalear su suelo, la herencia no-pensada de la tradición metafísica. Lo cierto es que ya esta descripción mínima del carácter de esta operación, descripción orientada por los contextos inmediatos de los primeros "usos" de ese concepto por parte de Derrida, tendría que desautorizar la interpretación habitual, y habitualmente crítica, de la deconstrucción como destrucción gratuita y nihilista del sentido y liquidación del buen sentido en el escepticismo posmoderno.

Derrida tenía la impresión que la palabra "deconstrucción" era una palabra entre otras muchas palabras, que iba a borrarse o que iba a ocupar un lugar ... Para él formaba parte de una cadena de vocablos como muchos otros, tales como Huella - Differance, las cuales también corrieron la misma suerte... Según Derrida sólo escribió esta palabra un par de veces, y le costaba recordar dónde y luego el término "ha saltado de pronto fuera del texto y otros se han apoderado de él y le han otorgado la importancia que se conoce... Cabe destacar que el éxito de esta palabra se produjo por el contexto, por la época en que dominaba generalmente el estructuralismo, y en el que la palabra clave era Estructura. Cuando alguien hablada de desectructura o desestructuración, alcanzaba una gran repercusión. Incluso al principio su desinterés por esta palabra llegaba a tal punto que rara vez hacía uso de ella, sobretodo en los textos anteriores a 1967. En La voz y el fenómeno (1967) no aparece de modo frecuente, al igual que en los artículos de La voz y la diferencia (1967).

El escrito que marcó la insistencia en su uso fue De la Gramatología (1967) y el mismo así lo sugiere: "Cuando elegí esta palabra, o cuando se me impuso, creo que fue en la De la Gramatología. ${ }^{4}$

Sin llegar a definirla Derrida nos dio una ideas clara de la deconstrucción: La deconstrucción es una serie de estrategias.

Derrida "desplaza sus acentos o su puntuación oculta, potencializa, formaliza, economiza enormes discursos, multiplica entre ellos los tratos, las transacciones,

HEIDEGGER, M. On Tine and Being, trad. Joan Stambaugh (Nueva York), p. 24.

4 DERRIDA, Jacques. (1967) De la Gramatología, México, Siglo XXI, 1998. 
el contrabando, el injerto, el parasitismo". 5

La deconstrucción ${ }^{6}$ irrumpe en un pensamiento de la escritura, como una escritura de la escritura, que por lo pronto obliga a otra lectura: no ya imantada a la comprensión hermenéutica del sentido que quiere-decir un discurso, a su fondo de ilegibilidad y de deseo de idioma-, a las fuerzas no intencionales inscritas en los sistemas significantes de un discurso que hacen de éste propiamente un "texto", es decir, algo que por su propia naturaleza o por su propia ley se resiste a ser comprendido como expresión de un sentido, o más bien "expone" éste como efecto $-\mathrm{y}$ con su legalidad y necesidad específica- de una ilusión para la conciencia.

La deconstrucción caracteriza un ethos de la lectura. Su atención, su trato, su cuidado se dedica a lo que en nombre de verdades férreas fue puesto al margen, fue reprimido: cada verdad esconde un secreto oscuro, existe sólo gracias a la fuerza de eso que es distinto; cada suposición (de la verdad) tiene su presuposición, algo que a la vez la posibilita y la imposibilita. Con esta figura paradójica, Ilamada por Derrida también "marca doble" (double-marque) o doble lazo, entra en acción una desjerarquización del significado, todo se pone en movimiento.

Si esto es así, habría que reconocer que en un principio un programa de interpretación e historia de la desconstrucción que intentase atenerse a lo que esta ha querido decir o habría querido decir, corre el riesgo de la mayor infidelidad hermenéutica. Sólo podría conjurar el peligro de esa infidelidad una retrospectiva o una mirada histórica al "origen" (pero dividido) de la desconstrucción que se esfuerce en leer allí, en las premisas y los primeros pasos o lugares de este pensamiento, el impulso inventivo y afirmativo, realmente "poiético", que lo transforma y lo encadena a una serie trópica inclausurable de conceptos y prácticas de otra interpretación de la experiencia (otra experiencia de la alteridad de lo otro), otra que la comprendida en y por una comprensión, un entendimiento y una razón autosituados en el centro.

Derrida apunta a "una textualidad general indiferienciada". La "deconstrucción"

5 DERRIDA, Jacques, La verdad en Pintura, Buenos Aires, Paidós, 2010. p. 21

6 A diferencia de muchas tendencias afamadas de la investigación científica cuyo inicio se desconoce, la deconstrucción tiene una fecha de nacimiento: octubre de 1966. En esos días, la John Hopkins University organizó un coloquio sobre "Los lenguajes críticos y las ciencias del hombre", en el que participaron destacados investigadores como George Poulet, Lucien Goldmann, Tzvetan Todorov, Roland Barthes, Jacques Lacan y Claude Lévi-Strauss. Era un certamen que pretendía acercar dos tradiciones críticas: la empirista angloamericana y la racionalista francesa. Asimismo, era la introducción del estructuralismo en el debate académico norteamericano. Participaba un joven crítico francés de origen argelino conocido por sus trabajos en torno a Husserl: Jacques Derrida. Éste dio lectura a su ponencia "Estructura, signo y juego en el discurso de las ciencias humanas", texto que constituye el acta de fundación de la deconstrucción. La mención al discurso en el título de la célebre participación nos ofrece una posible pista para la explicación de la gran difusión de la deconstrucción en ámbitos muy distantes a los de sus comienzos en el terreno filosófico.

7 CULLER, Jonathan, On deconstruction: theory and critism after structuralism. (Ithaca, N. Y., 1982), PP. $149-150$. 
viene a ser un "método" de lectura de textos, de operaciones textuales y estrategias heurísticas.

La caracterización realizada de la deconstrucción puede dar la idea de que se trata de un método: lo es y no lo es. Más bien, es una estrategia sin finalidad, un situarse en la inseguridad, como lo había planteado el pensamiento de Nietzsche, un ubicarse en las mismas estructuras de la metafísica que "ya" se están deconstruyendo. Esta deconstrucción la muestran los indecidibles, esos términos de la lengua que hacen patentes las fisuras de la misma, porque suponen una imposibilidad de decisión por algunos de los pares de opuestos.

\section{2.- Ricoeur ${ }^{8}$ : Derrida y la escuela de la sospecha.}

El proyecto de Derrida tiene su origen sobretodo en la tradición nietzscheana; tradición que finalmente se enmarca en lo que Ricoeur, agudamente, ha denominado "escuela de la sospecha" (Nietzsche - Freud - Marx). Lo determinante de esta "escuela" reside en el intento programática de "desenmascar" los motivos ocultos que subyacen tras la aparente neutralidad o positividad de la filosofía, la cultura y los signos en general. Pero no sólo la filosofía y las diversas formas culturales están afectadas a un engaño esencial, constitutivo, sino incluso la propia verdad no es más que otra forma de estratificación y mistificación histórica. Según la sugerencia de Nietzsche, finalmente, "las verdades son ilusiones de las que se ha olvidado que lo son". Uno de los méritos indudables de Derrida consiste precisamente no sólo en una inmersión excepcionalmente solvente en esta tradición de la "escuela de la sospecha", sino sobre todo en haber llevado, en cierto sentido, a culminación sus tendencias más profundas. Y es que para Derrida la tarea de desmontaje de la tradición "logocentrica" y "presentista" de la historia de la filosofía no consiste simplemente en develar un engaño o una ilusión para dar cuenta así de un "sentido originario" -como en la "genealogía" de Nietzsche-, sino en dar cuenta de las cesuras o las discontinuidades que afectan a toda traditio. La interpretación no nos entrega nunca los objetos en su verdadera presencia, sino como "huellas" que nunca se podrán hacer plenamente presentes. En toda interpretación, el sentido último queda pues perfectamente diferenciado, diferido (différence), desplazado, distanciado. $Y$ ello a tal punto que ni siquiera se puede saber dónde termina un "texto" y comienza otro: "Il n'y a pas de hors-texte", llega a afirmar Derrida. La hermenéutica de Derrida constituye sin duda una culminación de las tendencias más profundas de la denominada "escuela de la sospecha". Pero toda culminación, como todo límite, es un Janus bifrons: por una parte puede mirar hacia la serie del cual forma parte como una especie de cúspide, pero por otra

8 RICOEUR, Paul, (1969) El conflicto de las interpretaciones; Ensayos de hermenéutica, Editorial FCE, Buenos Aires, 2008

9 RICOEUR, Paul, (1965) Freud: una interpretación de la cultura, Editorial Siglo XXI, Madrid, 1999 ; (De l'interprétation. Essai sur Sigmund Freud, 1965) 
también puede mirar hacia el "otro lado del muro", hacia el silencio y la disolución. Cabe aquí la pregunta que el propio Foucault ha propuesto respecto de la hipertrofia de la interpretación: la intensificación de la sospecha y el "desenmascaramiento" suponen el paso constante de una máscara a otra hasta el infinito, sin jamás poder alcanzar un terminus ad quem. En tal caso, en estricto sentido, el proceso hermenéutico se agota en sí mismo y ya "no hay nada" que interpretar...

\section{3.- La deconstrucción: una escritura de la escritura; diferencia (différance) y sobreinterpretación.}

La deconstrucción como estrategia de lectura sospechosa, abusiva o sobreinterpretativa se despliega como un conjunto de estrategias (de lecturas), en un mecanismo textual por encima de las intenciones del autor y del texto mismo. -Lo que decimos sobrepasa siempre lo que creíamos querer decir y nos revela que finalmente no sabíamos de antemano lo que se dice a pesar de nosotros-.

El pensamiento esta anegado de lenguaje y su actividad -su ejercicio es una textura elucidante y plástica, que transita por laberintos y claustros, pero que su mejor expresión acontece al aire libre.

La cultura actúa como una cadena (red) de textos que se instruyen mutuamente y están en desplazamiento constante. Los textos deben ser leídos -de acuerdo a esta perspectiva- a la luz de otros textos, personas, obsesiones y retazos de información. "Sólo se puede cotejar una frase con otras frases, frases con las que está conectada mediante diversas relaciones inferenciales y laberínticas". ${ }^{10}$

Confirmando la antigua sospecha de los cabalistas, ante la vertiginosa deriva, ante el desplazamiento permanente, ante la sobre-interpretación; piénsese en la exégesis judía, el antiguo canon, donde se ha practicado con predilección el género del comentario. La exégesis judía da cabida a glosas de las Sagradas Escrituras, que generan asimismo otros comentarios, en un interminable proceso de despliegue textual. La prolijidad de los comentarios talmúdicos, la persistente presencia del texto central en las glosas marginales, así como su refinamiento filológico, caracterizan un tipo de escritura que ha hecho su aparición en la literatura moderna donde ha adoptado una forma secular. ${ }^{11}$ ¿Cabría esperar -

10 RORTY, Richard, "El Progreso del Pragmatista", en Interpretación y Sobreinterpretación, Umberto Eco, ED. Cambridge University Press, Madrid, 1997, Cáp.IV.

11 Este filisteísmo de la interpretación es más frecuente en la literatura que en cualquier otro arte. La obra de Kafka, por ejemplo, ha estado sujeta a secuestros en serie por no menos de tres ejércitos de intérpretes. Quienes leen a Kafka como alegoría social ven en él ejemplos cínicos de las frustraciones y la insensatez de la burocracia moderna, y su expresión definitiva en el estado totalitario. Quienes leen a Kafka como alegoría psicoanalítica ven en él desesperadas revelaciones del temor de Kafka a su padre, sus angustias de castración, su sensación de impotencia, su dependencia de los sueños. Quienes leen a Kafka como alegoría religiosa explican que K. intenta, en El castillo, lograr el acceso al cielo; que Joseph K., en El proceso, es juzgado por la inexorable y misteriosa justicia de Dios. -Otra obra que ha atraído a los intérpretes es la de Samuel Beckett. Los delicados dramas de la conciencia encerrada en sí misma de la Obra de Beckett -reducidos a un minimalismo sin concesiones -inmovilizados 
entonces- que el intelectual moderno posea un conjunto de competencias enciclopédicas, así como habilidades de avezado navegante de estos mares tormentosos -llenos de afluentes- o, más bien, debiera tenerse una clara conciencia de la insalvable inserción contextual de todo significado, sea éste el de una obra de arte o de una teoría física, y el consiguiente concurso simultaneo de una red de interpretes, interpretantes y exegetas. Aquí estamos ante la idea del texto como tejido -en continúa urdimbre-, en una glosa de crecimiento exponencial, que confiere al texto un grado de alejamiento y destierro donde el autor se pierde /se extravía/ a sí mismo y el sentido se disemina. ${ }^{12}$

\section{4.- La archi-escritura: Texto - Tejido.}

En la archi-escritura deconstructiva la fábrica de pensamientos opera como el oficio de tejedor, en el que un movimiento del pie agita millares de hilos, en el que la lanzadera sube y baja sin cesar, en el que los hilos se deslizan invisibles, en el que se forman mil nudos de un solo golpe: el filósofo viene después [éste es el retraso del filósofo, del llegado-tarde que analiza después y del que los estudiantes no aprenderán jamás el secreto del devenir-tejedor ni, por otra parte, por definición, y a causa de una alergia esencial, ningún secreto], y os demuestra que eso tuvo que ser así: lo primero es esto, lo segundo es esto, y por lo tanto lo tercero y lo cuarto son éstos, y si lo primero y lo segundo no existieran, lo tercero y lo cuarto no existirían tampoco. Los estudiantes de todos los países alaban este razonamiento, y sin embargo ninguno de ellos se ha convertido en tejedor.

Desde este nuevo concepto de escritura, los reenvíos entre los elementos posibilitan la formación de cadenas y de tejidos significantes. No sólo un elemento se suma a otros elementos para producir la cadena, sino que una cadena se cruza con otras cadenas para tejer un texto. El texto emerge de la transformación y en el entrecruzamiento con otros textos.

Por eso nada en los elementos, o en el sistema, está en alguna parte, simplemente presente o ausente, perceptible o imperceptible. De un extremo al otro no hay más que diferencias. Con ello, la constitución de todo signo, frase, cadena, texto y discurso, ingresa al juego de la diferencia y al trabajo de diferir el sentido. Se producen cadenas de cadenas, textos de textos, discursos de discursos, lecturas de lecturas y, en fin, huellas de huellas. En resumen, remontando la gramatología al principio mismo de la lingüística, el carácter diferencial del lenguaje implica una reforma del concepto de escritura, una archiescritura (escritura general de la huella, del grama o de la diferencia) lógicamente anterior a todas las oposiciones que justifican la subordinación de la grafía.

El neologismo de Derrida différance, traducible al español como "diferimiento",

físicamente- son leídos como una declaración sobre la alienación del hombre moderno, un testimonio más del nihilismo y las psicopatologías de la modernidad tardía Situados en el ámbito de esta escritura hipertextual en la que corremos el riesgo de perder al autor subsumido por el texto, extraviado por el laberinto o escindido en los constantes y expansivos comentarios.

12 DERRIDA, Jacques, La diseminación, Ed. Fundamentos, Madrid, 1997. 
parte del verbo "diferir", cuyos dos sentidos remiten, primero, al movimiento de retardar o dilatar la realización de algo y segundo, a la distinción, lo discernible, lo no idéntico. Ambos sentidos del verbo se refieren al espaciamiento entre dos artículos u objetos. En lingüística, Derrida emplea el concepto différance para señalar cómo el sentido de un producto textual siempre es pospuesto y nunca alcanza una significación plena y única. ${ }^{13}$

Se perfila entonces una escritura inédita, a partir de la cual queda excluido que cualquier elemento de la lengua pueda constituirse de un modo distinto al de la huella dejada en él por los demás, o que en su producción exista otra causa que la huella; en el decir derridiano, que tenga otro origen que el no-origen. De este modo, paradójicamente la gramatología parece llamada a deconstruir todos los presupuestos de una lingüística fonologocéntrica cuyos progresos, precisamente, permitieron abordarla.

Como se sabe, Derrida llama "fonocentrismo" al privilegio dado a la "presencia plena" que se cree encontrar en la voz, en la voz de la conciencia, en el sí mismo. Presencia que seria contaminada, traicionada, parasitada por un suplemento técnico: la escritura, que sería así una astucia artificial y artificiosa, un recurso para hacer aparecer como presente a la palabra cuando ella se encuentra en verdad ausente. La escritura sería así, un parásito, que se añade a una presencia plena de la que no forma parte, un virus que la infecta; por tanto el borrado de la huella, la supresión de los parásitos y la inmunización contra los virus han sido siempre mecanismos fundamentales de eso que llamamos metafísica.

\section{5.- Huella y sedimentos.}

La noción habitual de huella supone la idea de un original al que se refiere, del que es huella y que es hallado en la percepción. Sin embargo, el rasgo singular de la huella derridiana es precisamente la imposibilidad de encontrar originales en su presencia inmediata.

La imposibilidad de toda referencia originaria es una necesidad dictada por la estructura misma de la archi-escritura o archi-huella. Cada huella es la huella de una huella y así hasta el infinito.

A consecuencia de que no hay ninguna huella originaria, los presupuestos del origen y de la presencia son puestos en duda. Esto porque la huella sólo simula estar presente en un breve instante para inmediatamente ausentarse. En la huella, cada término se distingue a la vez que se ausenta de todos los demás términos. Por tanto, la huella no puede derivarse desde una presencia, desde un paradigma o Idea, desde una no-huella originaria, para quedar convertida en una mera copia, en una marca empírica, en una duplicación. ${ }^{14}$

13 DERRIDA, Jacques, La Différance, Conferencia pronunciada en la Sociedad Francesa de Filosofía, el 27 de enero de 1968. Publicada en Márgenes de la Filosofía. Trad. Carmen González Martín. Madrid: Cátedra, 1998.

14 La huella no es sino el simulacro de una presencia que se disloca, se desplaza y remite a otra 
La insistencia del texto en la textura de los hilos entrelazados, la madeja y sus nudos: es Geflecht, el entrelazamiento, es la palabra con la que Heidegger mienta la trama o la cadena en los lugares decisivos del pensamiento; es también die netzaritge Verstrickung. Esta densidad de la retórica del hilo y del nudo interesa en primer término por aquello a lo que apela y desafía: el análisis como operación metódica de desanudamiento y técnica de la desligazón. Trata de saber sacar los hilos, tirar de los hilos, según este arte del tejedor.

El pensamiento se elabora como un oficio de tejedor, en el que un movimiento del pie agita millares de hilos, en el que la lanzadera sube y baja sin cesar, en el que los hilos se deslizan invisibles, en el que se forman mil nudos de un solo golpe: el filósofo viene después [éste es el retraso del filósofo, del llegado-tarde que analiza después y del que los estudiantes no aprenderán jamás el secreto del devenirtejedor ni, por otra parte, por definición, y a causa de una alegría esencial, ningún secreto], y os demuestra que eso tuvo que ser así: lo primero es esto, lo segundo es esto, y por lo tanto lo tercero y lo cuarto son éstos, y si lo primero y lo segundo no existieran, lo tercero y lo cuarto no existirían tampoco. Los estudiantes de todos los países alaban este razonamiento, y sin embargo ninguno de ellos se ha convertido en tejedor.

\section{6.- Márgenes de la filosofía: sedimentos, diseminación y palimpsestos. ${ }^{15}$}

La deconstrucción es entonces es una estrategia de lectura, un conjunto de estrategias y tácticas. Derrida se opone a que la deconstrucción sea un método, porque el método es el modo de hacer algo cuyos pasos son siempre los mismos, es invariable en cambio la estrategia consiste en buscar qué método me sirve, busca innovar.

La deconstrucción entonces no es un método por ello se resiste a una definición definitiva, lo que no quiere es dar como una receta de cocina. La deconstrucción es una estrategia de lectura cuya particularidad está en el objeto específico que busca, que sería un mecanismo textual que sobrepasa o que ha sobrepasado las intenciones de quien produjo el texto en cuestión o las intenciones que pretende manifestar el texto mismo. ${ }^{16}$

La lectura deconstruccionista, o desconstructiva, trata de dar con el desliz textual en el que se manifiesta que el significado del texto no es justamente el que se está proponiendo, sino otro caso contradictorio. La deconstrucción busca la aporía; “... es la búsqueda vigilante de esas aporías, puntos oscuros o momentos de autocontradicción donde un texto traiciona involuntariamente la tensión entre la retórica y la lógica, entre lo que quiere decir manifiestamente y lo que no obstante

huella, a otro simulacro de presencia que, a su vez, se disloca, etcétera.

15 Palimpsesto del griego antiguo que significa "grabado nuevamente". Se llama palimpsesto al manuscrito que todavía conserva huellas de otra escritura anterior en la misma superficie, pero borrada expresamente para dar lugar a la que ahora existe.

16 DERRIDA, Jacques, La Différance, Conferencia pronunciada en la Sociedad Francesa de Filosofía, el 27 de enero de 1968. Publicada en Márgenes de la Filosofía. Trad. Carmen González Martín. Madrid: Cátedra, 1998. Introducción p.10. 
esta obligado a significar". ${ }^{17}$

Lo que busca la deconstrucción es apelar o lograr sacar el sedimento, para encontrar lo que está como substrato, las fuerzas no intencionales inscritas en los sistemas significantes en un discurso, aquello que se dijo pero que no se quiso decir, las fuerzas no intencionales inscritas en un discurso que hacen de este un discurso propiamente un texto, de una textura. Es decir algo que por su propia naturaleza o por su propia ley se resiste a ser comprendido como expresión de un sentido diverso, es decir hay conceptos que de tanto usarse en un sentido parecen adquirir un carácter unívoco pero en realidad tienen más acepciones, entonces acá uno encuentra otra cosa que está ahí dicha también.

En la lectura deconstructiva se trata de dar con un desliz textual donde sale a luz o se manifiesta que el significado del texto no es necesariamente el que se está proponiendo. Es una lectura sospechosa, de mala fe, una estrategia que intenta sorprender al texto en sus zonas marginales ${ }^{18}$, aquellas áreas de menor vigilancia, las notas a pie de página, la glosa o el comentario al margen, los bordes, los paréntesis o los trabajos poco relevantes de algunos autores, los lugares -en suma- donde que la vigilancia de quien escribe puede ser menor. Hay un interés por la marginalidad que busca rastrear los sentidos en lo aparentemente pasa desapercibido. No se intenta dar con un significado original y autentificador de lo real como presencia, más bien, lo que se quiere es dar lugar es a la multiplicidad de voces e intertextualidades.

La modernidad concebía al texto como un espacio cerrado, como texto "monumento", fijo, univoco, con un sentido original decidido de antemano por el escritor-autor-creador y recibido pasivamente por el lector; esto se contrapone al espacio polifónico, al texto como un espacio atravesado por relaciones de transtextualidad, en la perspectiva de Genette ${ }^{19}$ desde sus palimpsestos, ante el cual el lector ejerce una lectura siempre activa.

El autor es una localización: como se desprende de la lectura de Derrida, "nombrar desnombra, el nombre propio despoja, desapropia, expropia en lo que se llamará finalmente abismo de lo propio o de lo único". ${ }^{20}$ Tal desplazamiento de la propiedad del nombre hacia su desapropiación reside primeramente en la escritura, en la medida en que el autor no puede dominar al texto que escribe ni ponerse por encima de éste; es notable la cercanía de este planteo con la autonomía adjudicada por Ricoeur a la obra, esto es, su triple independencia respecto de las intenciones de su autor, su contexto inmediato de producción y sus destinatarios originales. ${ }^{21}$

Por más que intente evitarlo por medio de su firma, el escrito se libera de él en el

17 NORRIS, Christopher, Derrida, Cambridge, Harvard University Press, 1987, p. 19

18 DERRIDA, Jacques., (1972).“Firma, acontecimiento, contexto”, En Márgenes de la filosofía, Madrid, Cátedra, 2003

19 GENETTE, Gerard. Palimpsestos. La literatura en segundo grado,.Editorial Taurus, Madrid, 1989.

20 DERRIDA, Jacques, y BENNINGTON, Geoffrey, Jacques Derrida, Madrid, Cátedra, 1994

21 RICOEUR, Paul, Del texto a la acción, México, FCE, 2000., pp. 71-94. 
momento mismo de su inscripción, y ya no le pertenece. En este sentido, afirma Derrida que "respecto a la obra, el escritor es a la vez todo y nada", ${ }^{22}$ dejando así sentada la impropiedad con que se da inevitablemente la producción textual.

El autor como una localización: En síntesis, la crítica de Derrida a la Metafísica de la Presencia trata de la necesidad de fijar un origen, un creador, una figura original visible, en suma, un principio que es identificado con la figura paterna y con el orden y la jerarquía masculinos. Con este argumento, que en realidad desvela y denuncia una especie de falacia ad autoritatem, se pone en tela de juicio el afán de toda la metafísica tradicional, la cual siempre anhela un origen para todo acto, una presencia objetiva, un asidero del que partir, un creador, un Autor.

El autor es sólo una localización, es un locus, donde el lenguaje con sus ecos, repeticiones, intertextualidades, etc se cruza continuamente. Ha y que poner esto con relación de la metafísica de la presencia, es decir, con el afán de hallar un origen unificado, centralizado.

Esto significa que lo que están haciendo es quitarle el privilegio al autor que el tenga una autoridad que controle el significado, esto no es así porque en el momento en el que una obra se hizo independiente de lo que yo halla querido expresar, la obra cobra autonomía que puede ser leída, interpretada, puesta en relación con otra. Entonces la obra literaria se transforma en texto, en un tejido forjado a partir de la escritura del autor y de la lectura activa de los lectores que hacen conexiones de sentido sin tener en cuenta la primera intención de significado con ello se perfila la idea de que una obra altera su significado a través del tiempo y el texto cobra protagonismo. Nunca puede saberse quien escribe si el autor o los personajes que de alguna manera es quien le obligan.

Lo que decimos sobrepasa siempre lo que creíamos que debía decir y nos revela que finalmente no sabíamos de ante mano todo lo que se dice o está ahí dicho a pesar de nosotros,

Así no sería el autor el que produce el texto sino el texto el que produce el autor. El texto es el que da origen a la entidad del autor, el autor es creado por su propia escritura, como una especie de máscara tras la cual se ocultaría aparentemente el individuo real. Pero hay que reconocer la fragmentación del autor y estar atento a la pluralidad de sus voces y sus disfraces.

\section{7.- El parásito y la diseminación.}

Todo lo realizado por Derrida, para precisarlo, está dominado por la idea de virus, lo que podría llamarse una parasitología, una virología, donde el virus sería muchas cosas. Escribió acerca de esto en un texto poco conocido sobre las drogas Rhétorique de la drogue, ${ }^{23}$ "Points de suspension." En parte, el virus es un parásito que destruye, que introduce desorden dentro de la comunicación. Incluso

22 DERRIDA, Jacques, La escritura y la diferencia, Barcelona, Anthropos, 1989

23 DERRIDA, Jacques, Rhétorique de la drogue, 1990 [The Rhetoric of Drugs. an Interview Journal article by Jacques Derrida; Differences, Vol. 5, 1993] 
desde el punto de vista biológico, esto es lo que sucede con un virus; hace descarrilar un mecanismo de tipo comunicativo, su codificación y decodificación. Por otro lado, es algo que no está ni viviendo ni no-viviendo; el virus no es un microbio. $Y$ si se siguen estos dos hilos, el de un parásito que altera el destino desde un punto de vista comunicativo -modificando la escritura, la inscripción, y la codificación y decodificación de la inscripción- y que por otro lado no está ni vivo ni muerto. La intersección entre los virus biológicos y los virus de ordenador también tienen un alcance sociohistórico.

¿Qué ocurre cuando de un ensayo se extrae un "pasaje" y se lo "cita"? Cuando se halla escrito en el borde (al margen) o a pie de página. ¿Es la cita un parásito $^{24}$ intruso dentro del cuerpo del texto principal, o es el texto interpretativo el parásito que rodea y estrangula a la cita, su anfitrión? El anfitrión alimenta al parásito y hace posible su vida pero, al mismo tiempo, es aniquilado por él tal como se acostumbra decir que la crítica mata a la literatura.

Ahora, una de las versiones más aterradoras del parásito como hueste invasora es el virus. En este caso, el parásito es algo ajeno que no sólo tiene la capacidad de invadir el ámbito doméstico, consumir la comida de la familia y matar al anfitrión, sino la extraña habilidad de hacer todo eso y convertir mientras tanto al anfitrión en una multitud de réplicas prolíficas de sí mismo. El virus se encuentra en el límite incomodo entre la vida y la muerte. Desafía esa oposición dado que, por ejemplo no "come" sino sólo se reproduce. El patrón genético del virus se encuentra codificado de tal manera que puede ingresar en una célula anfitrión y reprogramar violentamente todo el material genético en ella, convirtiéndola en una pequeña fábrica de copias de sí mismo y destruyéndola al hacerlo. ${ }^{25}$ Así mismo, un germen, como un término que se disemina, lleva en sí su término. Fortificándose con su muerte. ${ }^{26}$

El lenguaje es un virus que se reproduce con gran facilidad y condiciona cualquier actividad humana, dando cuenta de su intoxicada naturaleza. En el contexto de esta escritura laberíntica en la que corremos el riesgo del extravío del autor perdido en el texto o por los constantes y expansivos comentarios, el texto como tejido en perpetuo hilar y trenzar que se hace, se traba a sí mismo y deshace al sujeto en su textura: una araña tal que se disolvería ella misma en las secreciones constructivas de su tela.

Ya en Papel Máquina Derrida anunciaba que en la esfera de los medios, las teletecnologías de producción de textos y las plataformas para su diseminación estaba en en marcha, la misma que hoy se encuentra desbordada por los sofisticados y poderosos dispositivos multimedia, virtualmente diversificables; ${ }^{27}$ la

24 Varios Autores: Bloom, Harold, Geoffrey Hartman, Paul de Man, Jacques Derrida, Geoffrey Hartman y Hillis Miller. Deconstrucción y crítica. Lingüística y teoría literaria, Editorial Siglo XXI, México, 2003.

MILLER, J. Hillis, "El crítico como huésped", en Deconstrucción y crítica (Derrida, Paul de Man, H. Bloom). Editorial siglo XXI, México, 2003..

26 DERRIDA, Jacques, La diseminación, Ed. Fundamentos, Madrid, 1997, pp. 485-486

27 De la máquina de procesamiento del texto (procesamiento electrónico de texto) y la representación virtual del conocimiento. 
Web viraliza los textos, los somete a la maquinalidad de la copia de la copia, sin fin. "No hay un centro, ni un original que funde las repeticiones, no existe el antepasado primordial, el origen primigenio. No hay origen que pueda servir para identificar el original del suplemento, ni para dominar su diseminación. Lo que reemplaza al centro-origen es una prótesis, un parásito' un suplemento". ${ }^{28}$

Así se podría decir con absoluta propiedad que William Burroughs es el precursor de la deriva, en el sentido situ de dérive y en la definición de Lyotard de driftwork. A partir de los textos de Burroughs es posible prever una geografía enteramente nueva, una especie de mapa de peregrinaciones en el que los lugares sagrados se han reemplazado con experiencias dromo-literarias: una verdadera ciencia de la psicotopografía. ${ }^{29}$

\section{BIBLIOGRAFÍA}

BARTHES, R.. (1953) El Grado Cero de la Escritura, Siglo XXI, México, 1999

DERRIDA, Jacques. (1998) De la Gramatología, Siglo XXI, México. [quinta edición en español. Primera edición en francés, 1967 , les éditions de minuit].

DERRIDA, Jacques, Márgenes de la filosofía, Cátedra, 1998, Madrid.

DERRIDA, Jacques, (1998), La tarjeta postal. De Freud a Lacan y más allá. México, Siglo XXI, 1986 ( $2^{\mathrm{a}}$ ed. aumentada, 2001).

DERRIDA, Jacques, (2001) La verdad en Pintura, Buenos Aires, Paidós, 2010

DERRIDA, Jacques, La diseminación, Ed. Fundamentos, Madrid, 1997.

DERRIDA, Jacques, La voz y el fenómeno, Valencia, Pre-textos, 1985.

DERRIDA, Jacques, La escritura y la diferencia, Barcelona, Anthropos, 1989.

DERRIDA, Jaques, Papel Máquina. Trad. de C. de Peretti y P. Vidarte. Madrid, Trotta, 2003.

DERRIDA, Jacques, Espectros de Marx, Trad. J.M. Alarcón \& C. de Peretti. Madrid, Trotta, 1995.

FOUCAULT, M. (1999) Las palabras y las cosas, Siglo XXI, México.

GENETTE, Gerard. Palimpsestos. La literatura en segundo grado, Editorial Taurus, Madrid, 1989.

NORRIS, Christopher, Derrida, Cambridge, Harvard University Press, 1987

RORTY, Richard. (1996) Consecuencias del pragmatismo. Tecnos, Madrid.

RICOEUR, Paul, (1969) El conflicto de las interpretaciones; Ensayos de hermenéutica, Editorial FCE, Buenos Aires, 2008

RICOEUR, Paul, (1965) Freud: una interpretación de la cultura, Editorial Siglo XXI, Madrid, 1999

28 POTEL, H., "Nietzsche y Derrida en la Red", Conferencia en la Alianza Francesa, Buenos Aires el 20 de octubre de 2006

29 VÁSQUEZ ROCCA, Adolfo, "William Burroughs: Literatura ectoplasmoide y mutaciones antropológicas. Del virus del lenguaje a la psicotopografía del texto", En NÓMADAS, Revista Crítica de Ciencias Sociales y Jurídicas - Universidad Complutense de Madrid, NÓMADAS. 26 | Enero-Junio.2010 (II), pp. 251-265. http://www.ucm.es/info/nomadas/26/avrocca2.pdf 